\title{
A providential ptosis revealing a tumor of the cavum
}

\section{Abstract}

Nasopharyngeal cancer is an endemic tumor of the Mediterranean rim. The usual clinical symptoms are dominated by cervical lymphadenopathy, otological and rhinological signs. Ophthalmological involvement is rarely indicative of the tumor and is seen especially at the late stage of the disease. The treatment of choice is radiotherapy associated with concomitant chemotherapy in certain evolved forms. We report a case of cavum cancer that was revealed by ptosis.

Keywords: ptosis, tumor of cavum
Volume 8 Issue 3 - 2018

\begin{abstract}
Youssoufou Souley Abdoul Salam, Laaribi Nisrine, Alsubari Naji Alwan, El Ouattassi Narjis, Reda Karim, Oubaaz Abdelbarre

Ophthalmology Service MohamedV Military Hospital, Morocco
\end{abstract}

Correspondence: Youssoufou Souley Abdoul Salam, Université MohamedV de Rabat, Ophtalmology Service MohamedV Military Hospital, Rabat, Morocco, Tel +002I 2674254784 , Email abdoulsalam_y@yahoo.fr

Received: March 16,2018| Published: May 02, 2018

\section{Introduction}

The nasopharyngeal neoplasm is an endemic tumor of the Mediterranean region..$^{1-3}$ The main clinical picture is dominated by otological and rhinological signs, as well as cervical lymphadenopathy. An ophthalmological symptom rarely points to the tumor and is seen, moreover, in the late stage of the disease. We will present in this paperwork, a case of cavum cancer revealed by an ocular manifestation.

\section{Case report}

A sixty-four year old patient with a recently diagnosed medical history of unregulated high blood pressure, consulted for severe

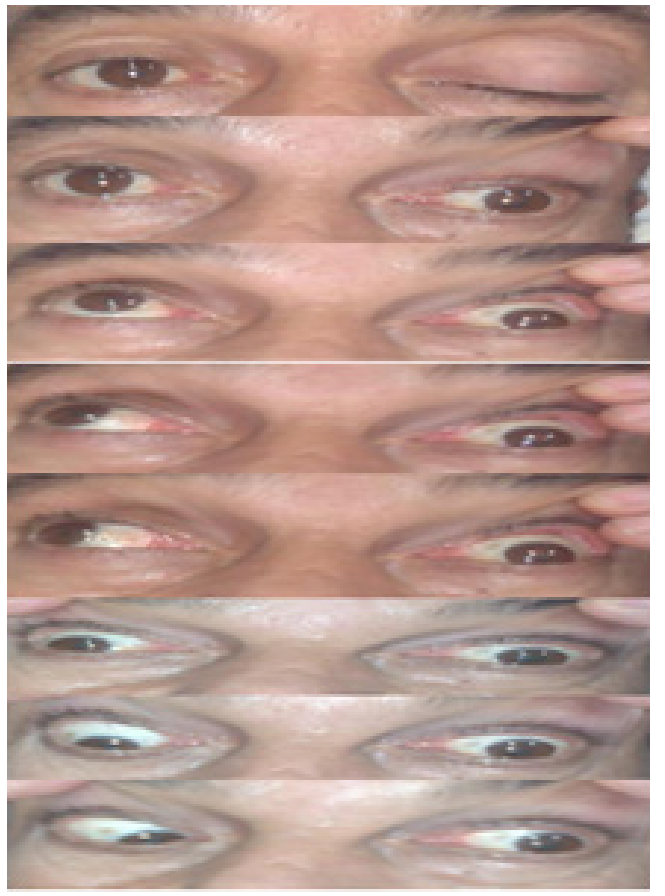

ptosis of the left eye associated with pain along the ophthalmic nerve's territory which was progressing rapidly within 20 days. The ophthalmological examination revealed a best-corrected visual acuity of $7 / 10$ for the right eye and 3/10 for the left. Manual rising of the left upper eyelid unveiled a divergent eyeball associated with a subtotal restriction of eye movement (Figure 1). Further examination with the slit lamp showed a nonreactive mydriasis. The cerebral MRI indicated a malicious tumor of the left posterolateral cavum wall invading the left cavernous sinus and the hypopharynx (Figure 2). A biopsy was conducted and confirmed a poorly differentiated epidermoid carcinoma. The patient's assessment of extent was negative, therefore, benefiting of several radio-chemotherapy sessions. Follow-ups had shown an improvement of visual acuity, decreased ptosis and increased ocular motility (Figure 3).

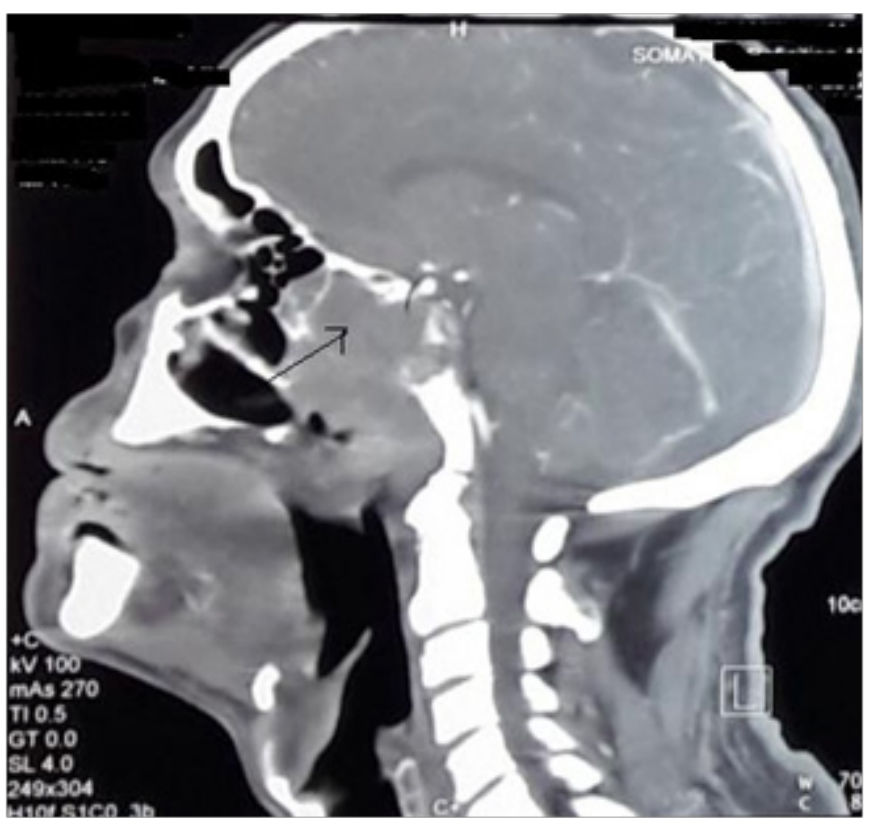

Figure 2 CT scan image showing the cavum tumor.

Figure I Oculomotor examination showing oculomotor paralysis. 


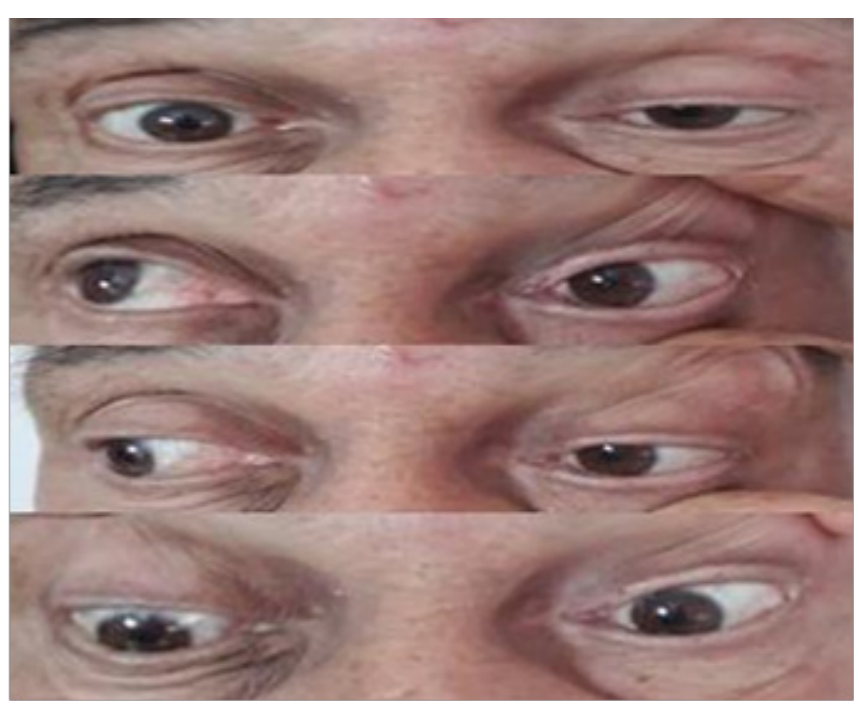

Figure 3 Decrease of ptosis under treatment.

\section{Discussion}

The mechanisms and causes of ptosis are of different variety. A complete ocular motility examination is systematic, especially if a neurological cause of the ptosis is suspected. For our patient, the "providential ptosis" hid an ophthalmoplegia by restricted ocular motility indicating a paralysis of the ocular nerve. A compressive optic neuropathy should be thought of whenever there is a common oculomotor nerve palsy associated with a cavernous sinus syndrome, primarily when a compressive lesion is highly suspected, such as tumors or aneurysms. It goes without saying that cerebral imaging is of crucial importance for the diagnosis. Cavum cancer is not rare in the Mediterranean area. ${ }^{1,2}$ It is usually manifested by high dysphagia, unilateral earache and, quite often, isolated cervical lymphadenopathy, which are sometimes bilateral. More rarely, the signs may be neurological with one or more cranial nerves, especially III, IV, VI, IX, X, XI. An ocular symptom can reveal cavum cancer in its very late stage. Treatment is based on radiotherapy of the pharynx and ganglionic areas in large doses. Computerized dosimetry conditions optimal irradiation. The place of surgery is usually limited to that of a remedial adenectomy. Neoadjuvant chemotherapy is indicated in locoregional and, or general forms. ${ }^{1}$

\section{Conclusion}

Cavum cancer is a frequent tumor in the Mediterranean area and in Morocco. Its diagnosis is usually late due to its deep anatomic localization and its misleading symptomatology, which allows the tumor to invade the base of the skull and cause various nerve affections. Ocular involvement in cavum neoplasms is quite rare and is revealed in the late stage of the disease.

\section{Acknowledgements}

None.

\section{Conflict of interest}

The author declares that there is no conflict of interest.

\section{References}

1. Fleury B, Biston MC, Montbarbon X, et al. Cancer du cavum de l'adulte. Cancer Radiother. 2010;14(Suppl 1):S23-S33.

2. Bourezgui M, Rafai MA, Boulaajaj FZ, et al. Atteintes visuelles et oculomotrices révélatrices d'un carcinome du cavum. NPG Neurologie Psychiatrie - Gériatrie. 2009;9(50):110-113.

3. Busson P, Ooka T, Corbex M. Carcinomes nasopharyngés associés au virus EB: de l'épidémiologie à la thérapeutique. Médecine/Sciences. 2004;20(4):453-457. 